\title{
Analysis of Hydrogen Show That Hydrogen Is the Best Fuel of Future in Bangladesh
}

\author{
Mahadehe Hassan \\ Hydrocarbon Unit (HCU), Energy and Mineral Resources Division, Ministry of Power, Energy and Mineral Resources, Dhaka, Bangladesh \\ Email address: \\ mahadehe@hcu.org.bd

\section{To cite this article:} \\ Mahadehe Hassan. Analysis of Hydrogen Show That Hydrogen Is the Best Fuel of Future in Bangladesh. Journal of Energy, Environmental \& \\ Chemical Engineering. Vol. 6, No. 3, 2021, pp. 57-64. doi: 10.11648/j.jeece.20210603.12
}

Received: June 28, 2021; Accepted: July 12, 2021; Published: July 23, 2021

\begin{abstract}
Bangladesh is a mid-income country. Her GDP growth rate is one of the world's largest. For any country, development is the precondition for continued growth of GDP. And the main driving force of the country's development is energy. Proper use of hydrogen fuel is essential to meet the country's growing energy demands as well as to lift up from a mid-income country to a developed country. Hydrogen fuel will play a vital role in implementing Vision-2041. In the context of globalization and open market economy, there is no alternative to the discovery of hydrogen fuel of Bangladesh and its proper management and planned use. Hydrogen is a sustainable \& renewable fuel. It is very promising to add hydrogen as fuel to the fuel mix of Bangladesh like coal and gas. Therefore, this study analyzes the Hydrogen is the best fuel of Bangladesh in accordance with Vision 2041. The research focuses on the following points: (i) Analysis of hydrogen creation, uses and storage; (ii) Analysis of hydrogen in renewable energy integration; (iii) Analysis of Hydrogen Fuel Cell Vehicle illustration; (iv) Analysis of hydrogen production and Electricity Production by Hydrogen; (v) Analysis of Green Hydrogen by Water Electrolysis and Green Hydrogen production cost.
\end{abstract}

Keywords: Fossil Fuel, Hydrogen, Splitting, Renewable Energy, Electricity, Carbon Emission, Electrolysis

\section{Introduction}

Hydrogen is the simplest and most abundant element on earth-it consists of only one proton and one electron. Hydrogen can store and deliver usable energy, but it does not typically exist by itself in nature and must be produced from compounds that contain it.

Hydrogen is a clean fuel that, when consumed in a fuel cell, produces only water, electricity, and heat. Hydrogen and fuel cells can play an important role in our national energy strategy, with the potential for use in a broad range of applications, across virtually all sectors-transportation, commercial, industrial, residential, and portable.

Hydrogen and fuel cells can provide energy for use in diverse applications, including distributed or combined-heat-and-power; backup power; systems for storing and enabling renewable energy; portable power; auxiliary power for trucks, aircraft, rail, and ships; specialty vehicles such as forklifts; and passenger and freight vehicles including cars, trucks, and buses.

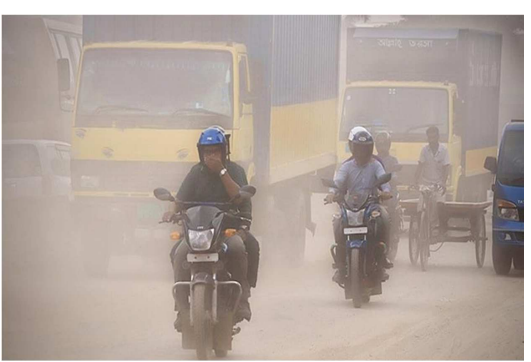

Figure 1. Dhaka city has the one of the worst polluted air in the world [5].

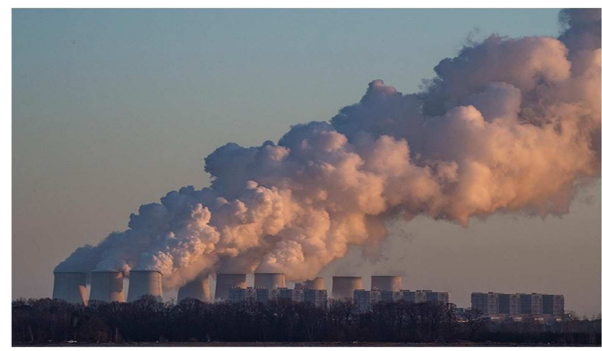

Figure 2. Carbon Emissions [5]. 


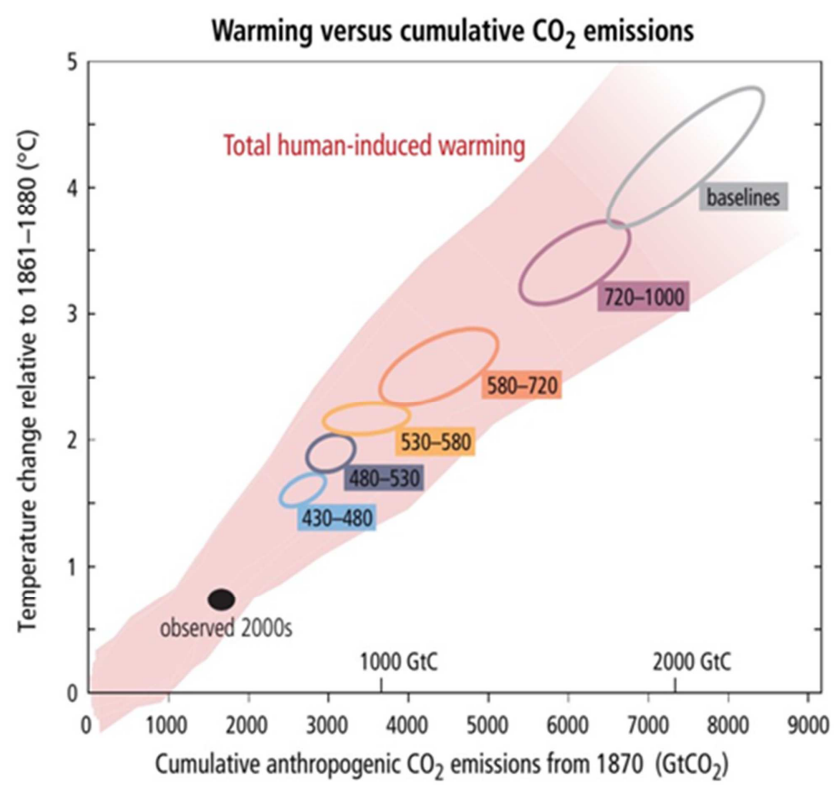

Figure 3. Carbon Emissions and Climate Change.

Intergovernmental Panel on Climate Change (IPCC), Climate Change 2014 Synthesis Report - Summary for Policy Makers, 2014.

Show the above figure limiting total human-induced warming to less than $2^{\circ} \mathrm{C}$ relative to the period $1861-1880$ with a probability of $>66 \% 7$ would require cumulative $\mathrm{CO} 2$ emissions from all anthropogenic sources since 1870 to remain below about $2900 \mathrm{GtCO} 2$ (with a range of 2550 to 3150 GtCO2 depending on non-CO2 drivers). About 1900 GtCO2 had already been emitted by 2011 [3].

\section{Analysis of Hydrogen Creation, Uses and Storage}

Electrolysis via renewables is a method in which electricity splits water into hydrogen and oxygen. The hydrogen can then be stored, and the oxygen can be released into the air or stored.

Reformation from methane is another way of producing hydrogen. Carbon capture storage (CCS) technology can capture the carbon dioxide that is produced from the process.

\subsection{Fossil Fuel to Hydrogen Fuel to Generate Electricity Strategy}

Fossil Fuel: Natural Gas, Petroleum and Coal

a. Main constituents of fossil Fuels are hydrogen and Carbon

b. $\mathrm{CO}_{2}$ is always Produced in Fossil Fuel combustion

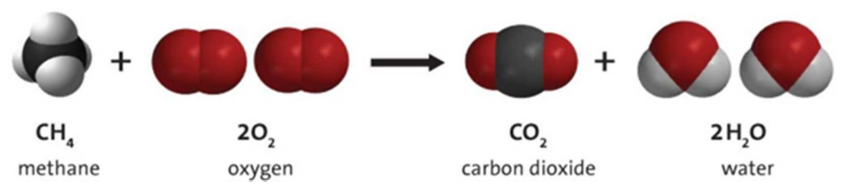

Making H2 Via Water Splitting:

Water + Energy $\rightarrow$ Hydrogen + Oxygen

$$
2 \mathrm{H}_{2} \mathrm{O}+\text { Energy } \rightarrow 2 \mathrm{H}_{2}+\mathrm{O}_{2}
$$

Hydrogen Fuel to Generate Electricity:

$$
\begin{gathered}
\text { Hydrogen }+ \text { Oxygen } \rightarrow \text { Water + Energy } \\
2 \mathrm{H}_{2}+\mathrm{O}_{2} \rightarrow 2 \mathrm{H}_{2} \mathrm{O}+\text { Energy [6] }
\end{gathered}
$$

\section{2. $\mathrm{H}_{2}$ in Renewable Energy Integration}

In hydrogen production pathways based on renewable energy sources, produced and stored hydrogen can be employed for various applications as shown in below [8].

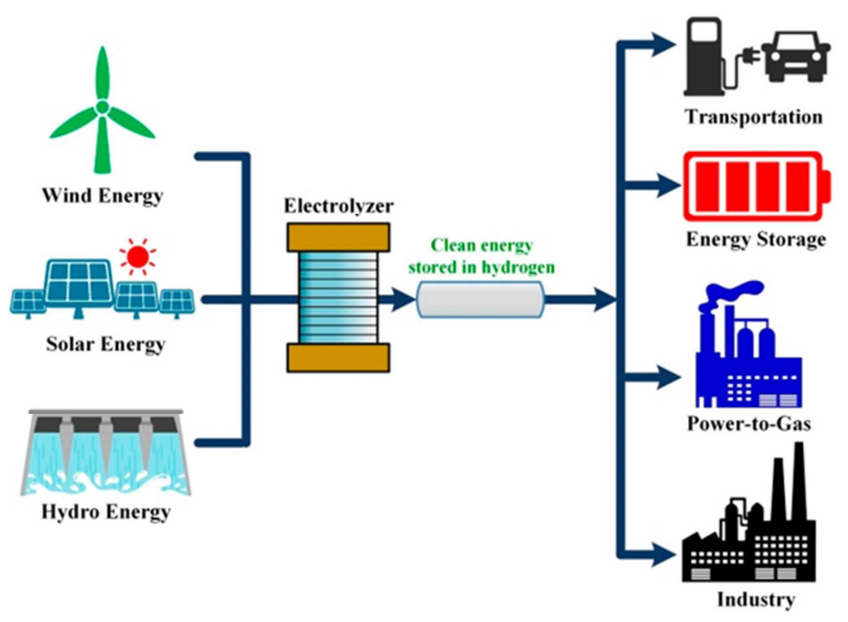

Figure 4. Overview of applications based on water electrolysis process supplied by renewable energy sources.

Transportation: Hydrogen allows supplying hydrogen fueling stations for fuel cell electric vehicles. Hydrogen is stored in pressurized tanks (around 700 bar) and supply PEM fuel cells to power electric motors [8]. Some car manufacturers have even developed fuel cell electric vehicles such as Toyota (Mirai model), Hyundai (Tucson model), and Honda (Clarity model).

Energy storage: To face intermittent energy disturbances, the surplus energy at times of low energy demand can be stored in hydrogen, then used to balance the grid in case of high energy demand.

Power-to-Gas: It consists of converting hydrogen through the methanation process into a green natural gas to be injected in pipeline and underground facilities. It represents an alternative storage capacity, which can be employed where and when it is required most and makes the power system more flexible.

Industry: Hydrogen can be used in different industrial processes such as chemical (e.g., ammonia synthesis, methanol production), metallurgic (e.g., metalworking, carbon steels), and electronic (e.g., semiconductors production).

\subsection{Uses of Hydrogen}

Transport: Improved fuel cell technology for cars, buses, trains and ferries demonstrating hydrogen use where its rapid refueling time and higher efficiency density give it an 
advantage over batteries.

Industry: Heavy industry, for example glassmaking and pottery, use high temperature furnaces that emit large volumes of $\mathrm{CO}_{2}$. A move to hydrogen offers a big opportunity to decarbonize. Steel making also has the potential to export hydrogen to the grid, as a by-product of the production process.

Homes: Using existing gas infrastructure hydrogen could provide a safe and reliable source of energy for heating, lighting and appliances, where retrofit for electrification could prove costly.

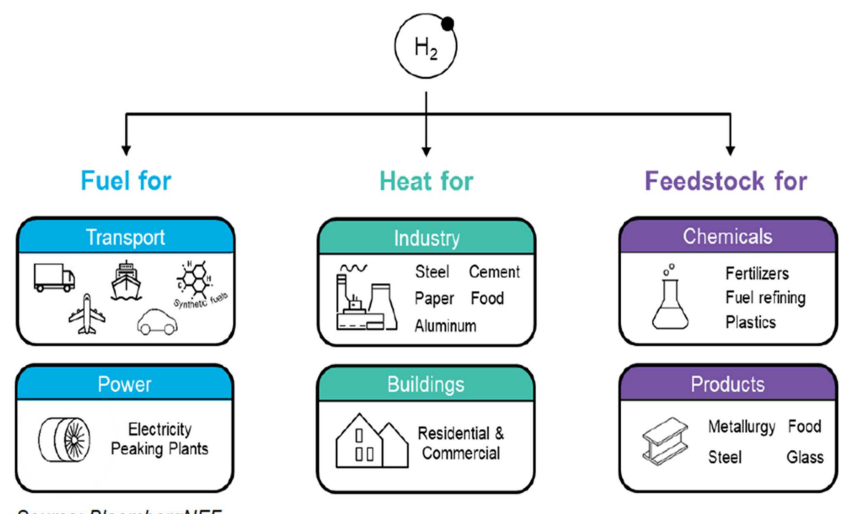

Source: BloombergNEF

Figure 5. Uses of Hydrogen for different sector.

Heat for Industry: The two-degree scenario calls for $\mathrm{CO}_{2}$ emission reductions of $30 \%$ in this sector.

Buildings: $\mathrm{H}_{2}$ can be blended with natural gas, methanized, or used in its pure form.

Feedstock for chemical: 55 million tons of hydrogen as feedstock and Creates some 350 to $400 \mathrm{Mt} \mathrm{CO}_{2}$ per year [2].

Transportation:

1. The two-degree scenario requires reducing emissions by
$40 \%$ until 2050 [4].

2. Hydrogen is a key technology in a decarbonized transport system.

3. More than 80 million zero-emission vehicles will need to be on the roads by 2030 - just 12 years from today (Source: Hydrogen Council 2017). [4]

4. Transportation contributes to a third of US greenhouse gas emission.

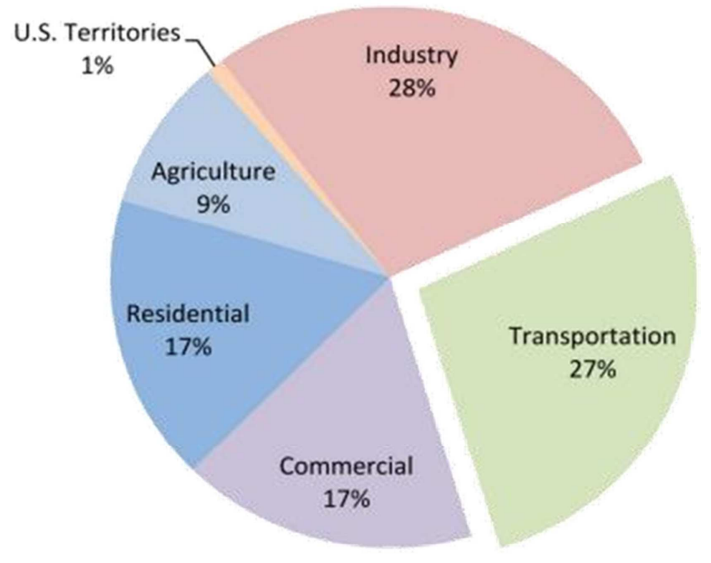

Share of U.S. GHG Emissions by End-Use Sector

Figure 6. Share of US GHG Emission by sector wise uses.

\subsection{Need for Energy Storage}

Some $20 \%$ of variable electricity has to be converted to hydrogen to guarantee a secure energy supply every time of the day and year [1].

\section{Overview of study results}

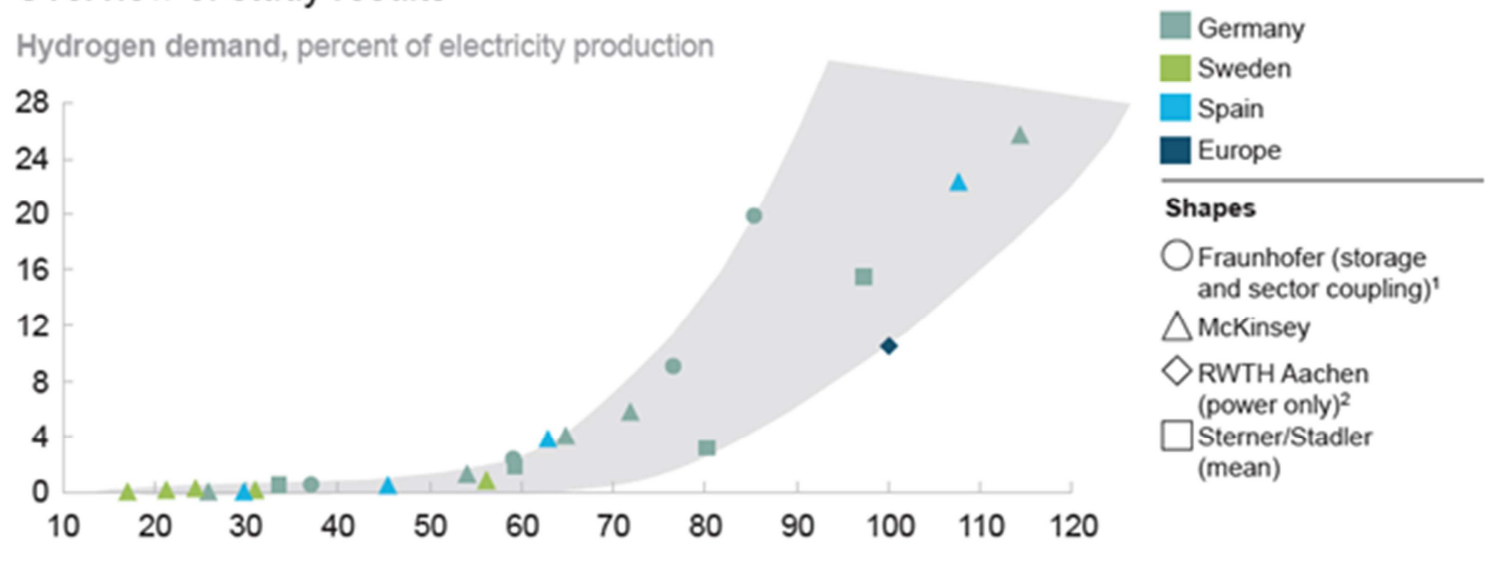

Variable renewable energy, percent of electricity demand

\footnotetext{
1 Least-cost modeling to achieve $2^{\circ} \mathrm{C}$ scenario in Germany in 2050 in hour-by-hour simulation of power generation and demand, assumptions: no regional distribution issues (would increase hydrogen pathway), no change in energy imports and exports 2 Simulation of storage requirements for $100 \%$ European RES; only power-sector storage considered (lower bound for hydrogen pathway) SOURCE: Fraunhofer Institute for Solar Energy Systems ISE, 2017; BMW; RWTH Aachen; Sterner and Stadler (2014); McKinsey
}

Figure 7. Hydrogen demand, percent of electricity production vs variable renewable energy, percent of electricity demand. 


\section{5. $\mathrm{H}_{2}$ Fuel Cell Vehicles}

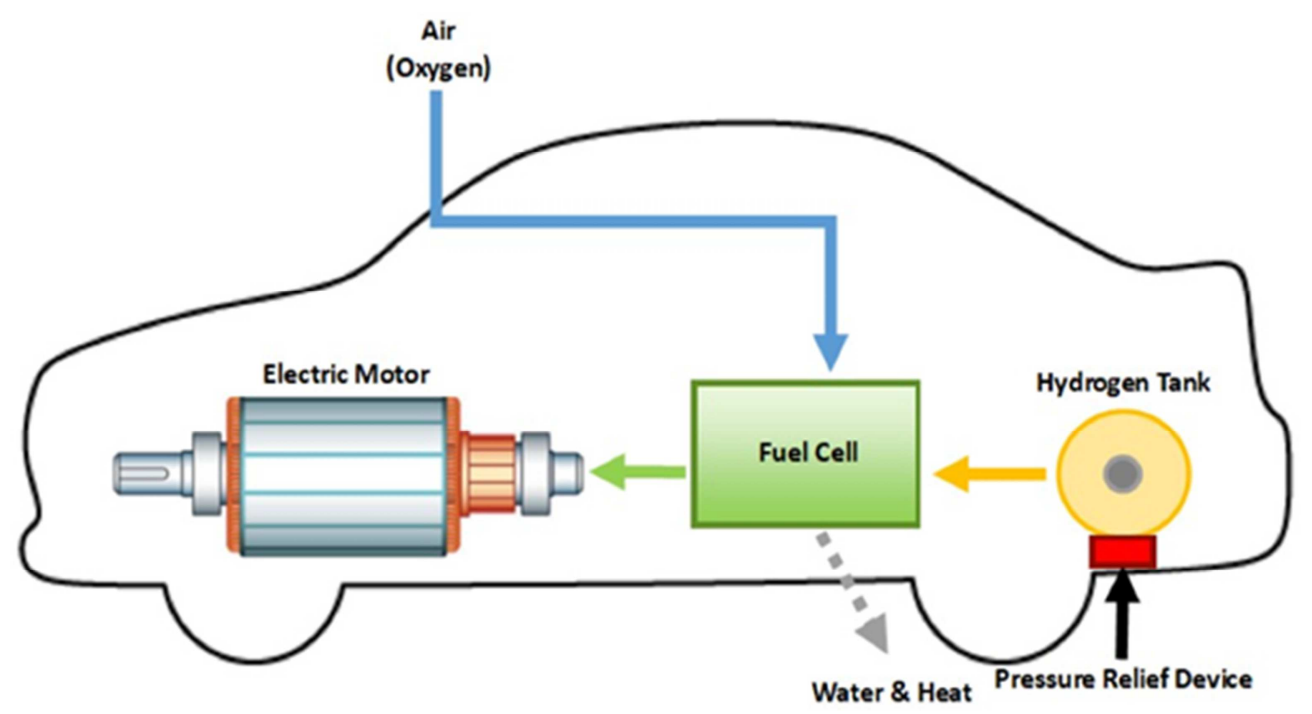

Figure 8. Hydrogen Fuel Cell Vehicle illustration.

Figure 8 [9] illustrates the process undergone to transform hydrogen fuel into energy. Hydrogen is passed into the fuel cell along with air. Inside the fuel cell, the hydrogen atom is split into protons and electrons. The electrons, and specifically the steady flow of electrons, are the electricity used to operate the electric motor that drives the vehicle. While the fuel cell is producing electricity, the protons from the hydrogen combine with oxygen from the air to produce water.

The only exhaust that HFCEVs produce is water vapor. HFCEVs are electric vehicles, so most HFCEVs don't employ any backup power systems that run off of other fuels. This means that HFCEVs do not have a gasoline or diesel storage tank on board. While the cost of hydrogen is dependent on transportation and generation methods, it is competitive with that of gasoline and can be cheaper.

\subsection{Electricity Production by Hydrogen}

In order to obtain electricity from hydrogen it reacts with oxygen, obtaining electricity and water. The device responsible for carrying out this reaction is called fuel cell. In this way, the generation of electricity with fuel cells from hydrogen is $100 \%$ clean, and also as a byproduct drinking water is generated.

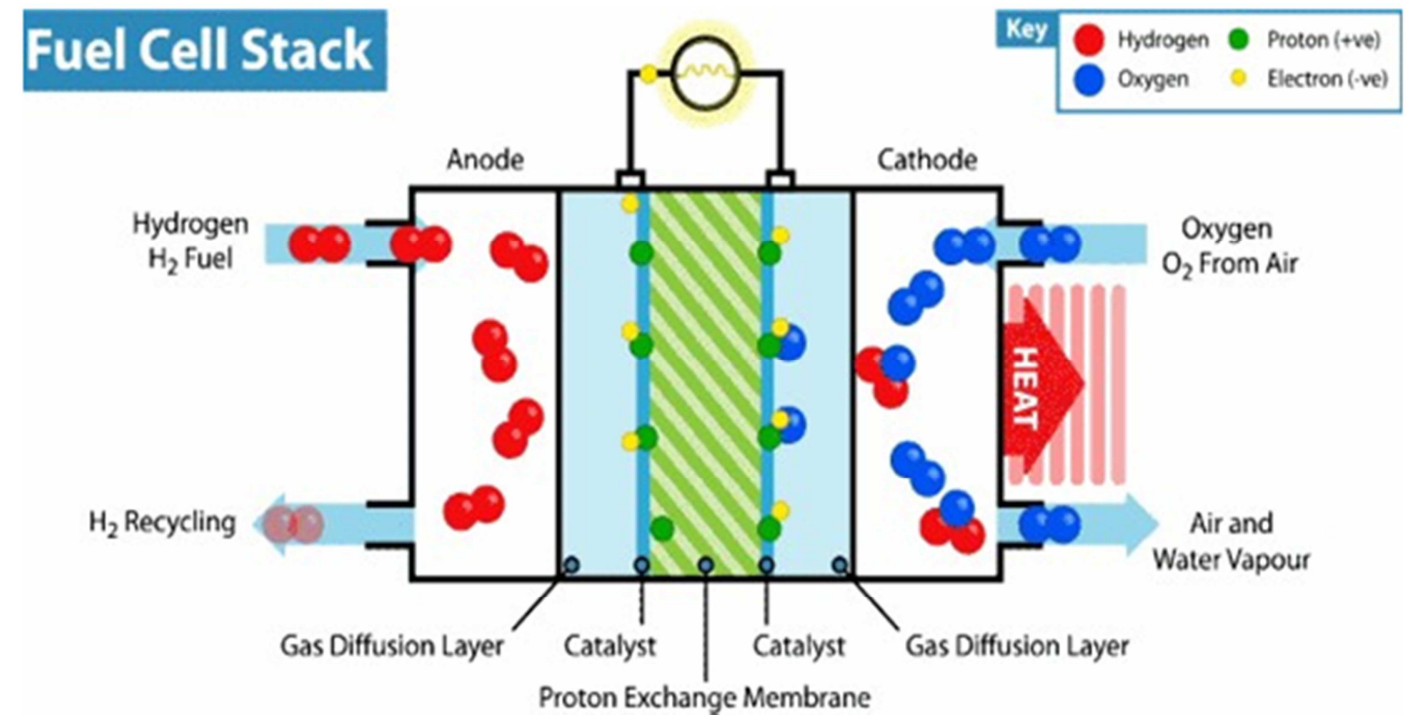

Figure 9. Working principle of hydrogen fuel cell [10].

\subsection{The Hydrogen Fuel Cell Electric Car in the Transport Sector}

The hydrogen fuel cell electric cars (FCEV) would reduce local air pollution because, like battery electric cars (BEV) have zero emissions of polluting gas [10]. 


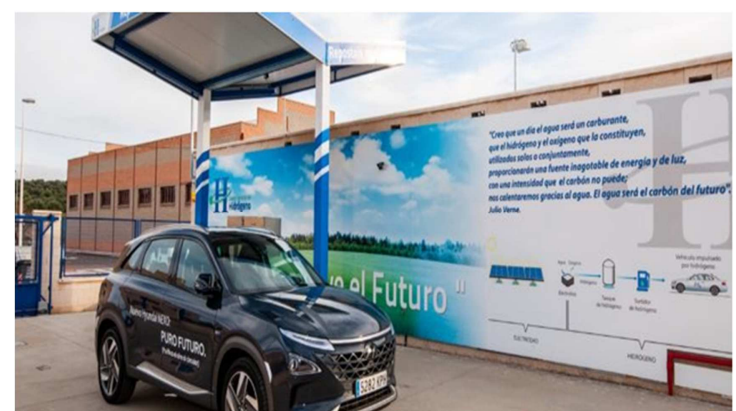

Figure 10. First hydrogen stack vehicle registered in Spain. Hundai Nexo [10].

\subsection{Hydrogen Production}

a. Almost all of the current hydrogen is produced from hydrocarbons such as natural gas and coal.

b. Responsible for the emission of around $830 \mathrm{Mt}$ of $\mathrm{CO} 2$ per year, equivalent to the combined $\mathrm{CO} 2$ emissions of the United Kingdom and France [7].

Coal Gasification

Reforming of Natural Gas

Steam-methane reforming reaction

$\mathrm{CH}_{4}+\mathrm{H}_{2} \mathrm{O}$ (+ heat) $\rightarrow \mathrm{CO}+3 \mathrm{H}_{2}$

Water-gas shift reaction

$\mathrm{CO}+\mathrm{H}_{2} \mathrm{O} \rightarrow \mathrm{CO}_{2}+\mathrm{H}_{2}$ (+ small amount of heat)

\subsection{Green Hydrogen by Water Electrolysis}

a. Renewable energy sources: solar photovoltaic and wind energy.

b. Migrating all current hydrogen production would represent an electricity demand of $3600 \mathrm{TWh}$, more than the annual electricity generation of the entire European Union [10].

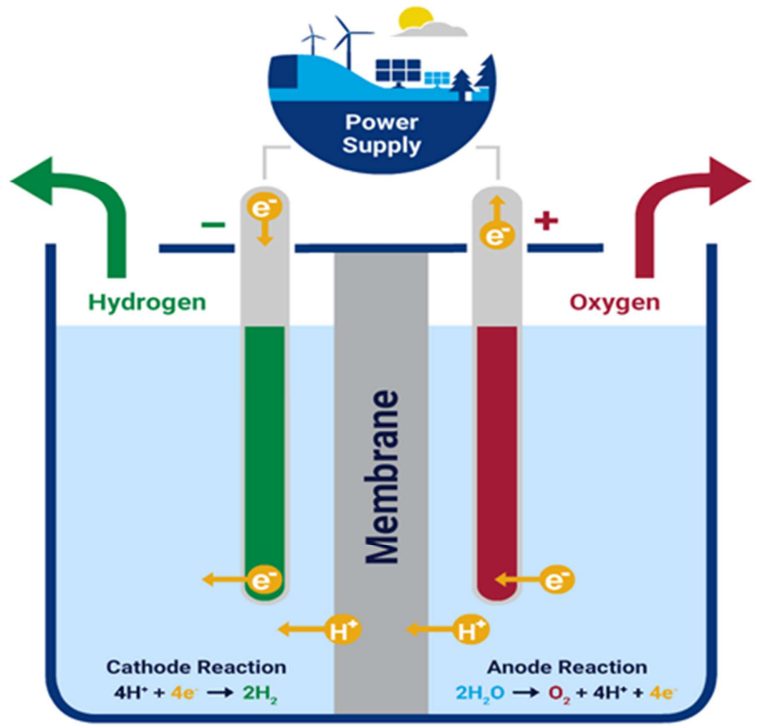

Figure 11. Obtaining green hydrogen by water electrolysis from renewable energy sources [10].

\subsection{Green Hydrogen Production Cost}

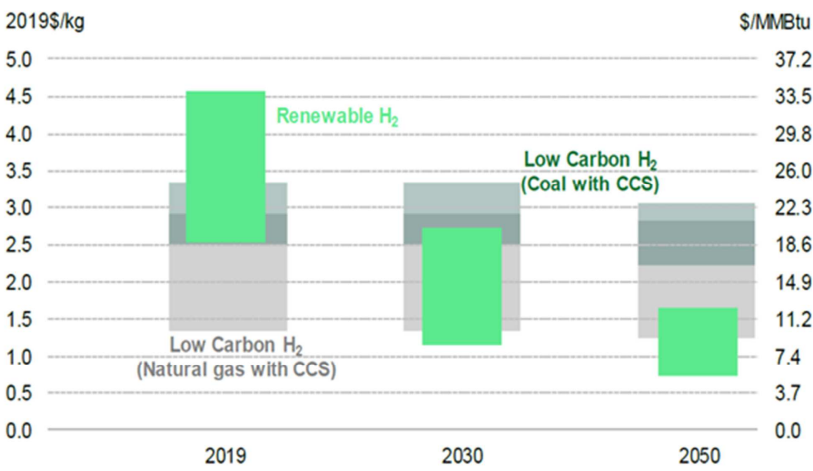

Source: BloombergNEF. Note renewable hydrogen costs based on large projects with optimistic projections for capex. Natural gas prices range from \$1.1-10.3/MMBtu, coal from \$30-116/t.

Figure 12. Forecast global range of levelized cost of hydrogen production from large projects [2].

\section{Result and Discussion}

Experiments have shown that Hydrogen is a sustainable \& renewable fuel. It is very promising to add hydrogen as fuel to the fuel mix of Bangladesh like coal and gas. The fuel value of hydrogen $(142 \mathrm{~kJ} / \mathrm{g})$ is three times of traditional fuel. Hydrogen fuel system doesn't require large infrastructure development and investment along with traditional fuel system. There is no harmful emission to the environment from Hydrogen fuel cell based transportations and combined heat \& power (CHPs) system. $33.33 \mathrm{kWh}$ energy come from $1 \mathrm{~kg}$ of hydrogen whereas $12 \mathrm{kWh} / \mathrm{kg}$ and $14.7 \mathrm{kWh} / \mathrm{kg}$ from Petrol and $\mathrm{CNG}$ accordingly.

Hydrogen Fuel Cell car run $100.131 \mathrm{~km}$ using $1 \mathrm{~kg}$ of hydrogen whereas a traditional car run $16 \mathrm{~km}$ using $1 \mathrm{~kg}$ of petrol. An amount of 0.08-0.13 kg hydrogen can be produced from $1 \mathrm{~kg}$ of biomass (using biomass gasification). Market price of pipe line used $1 \mathrm{~kg}$ hydrogen is USD 2.5-3.5. A good amount of unused Biomass of Bangladesh could be a valuable resource to produce hydrogen. BCSIR has designed \& installed biomass gasification based hydrogen production plant at BCSIR laboratories, Chattogram campus. A good number of hydrogen production plant like HELC pilot plant certainly could add energy to the national grid and to the transportation sector. It is a milestone effort to set up and expand Hydrogen energy industry in Bangladesh. The technology makes us self-reliant in producing energy using domestic feedstock. Hydrogen is one of potential resources to meet the $10 \%$ renewable energy target of Bangladesh. It is right time to take proper planning \& initiatives of energy transition to hydrogen like other countries.

\section{Challenges the Hydrogen Fuel Needs to Overcome to Succeed}

The Bangladesh needs to overcome numerous challenges over the coming years to allow organizations, industry bodies and individuals to feel confident in investing in the hydrogen 
economy supply chain.

(a) Attracting Demand

Without growing demand, the large scale production of hydrogen will not happen. This demand could come from a number of sources, all of which require a broad range of end user appliances and equipment that is standardized, desirable, safe and affordable. However, without a strong supply chain which acts to reduce the costs of hydrogen, and provide confidence in the capability of industry to deliver a secure and affordable fuel, consumers and public and private sector buyers will be reluctant to purchase hydrogen products.

This is the dilemma that needs to be addressed: how to incrementally build demand and supply in the most cost-effective manner.

(b) Enabling infrastructure and Investment

Hydrogen requires infrastructure to get it from source to end user. The capital investment needed is significant and reliant on long term indication and forecasts. If new business models and new tariff arrangements are to emerge and thrive, policy-makers need to establish a robust, credible and flexible framework. This may not necessarily take the form of the traditional regulated network model. Especially if it based on a modular approach that increases network size and applications over time, as demand for hydrogen grows incrementally on a regional or market basis.

The end goal is to have a sustainable hydrogen economy with both the production and infrastructure in place and importantly-a demand form and users.

(c) One approach to policy

Government has an essential role to play hydrogen to establish its place in the Bangladesh energy system. Policy makers have both the opportunity to stimulate demand and the tools to ensure hydrogen is able to compete on a level playing field with other decarbonisation pathways. The challenge for government is to establish how it can most effectively stimulate the hydrogen fuel, both for the established energy players and disruptive market entrances. The challenge for the industry is to speak to government with one voice about what is needed.

Ultimately it is consumer demand that will support and sustain the business case for a future hydrogen fuel. The perception of hydrogen must change so it is seen as a trusted alternative to current fuels and as a means to decarbonise. A strong narrative is required around how hydrogen can deliver benefits to consumers and value to investors. It is about providing consumers a choice and allowing the transition from one fuel source to another fuel source. Continuing to bring together key players in collaborative way will help push the cause further.

Raising the awareness about the challenges the different parties face, identifying solutions and establishing relationships across the supply chain and government is an essential next step.

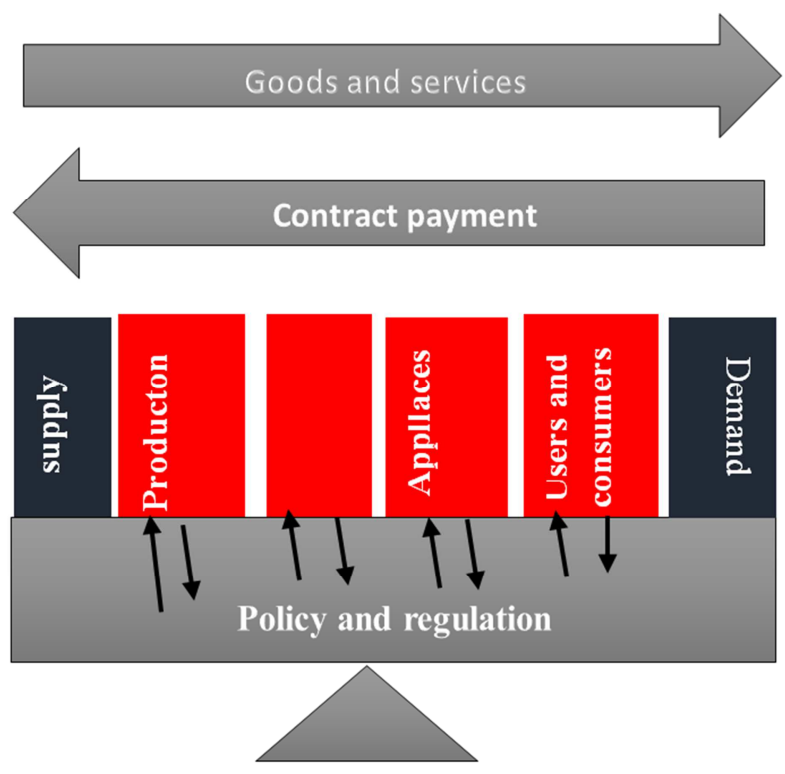

Figure 13. Policy and Regulation.

\section{Strategies to Achieve the Hydrogen Fuel System}

A clear road map and vision should be established to make the hydrogen fuel system achievable. Below is some key consideration which can help the industry overcome the challenges and grasp the hydrogen opportunity. These focus areas have been a discussion point throughout the public and private sectors from transport to large scale consumer. Some are short term achievements whilst others are long term initiatives, but all essential to a successful decarbonized energy system.

One thing is certain-action needs to start now

(a) Bring Consumers along:

Consumers are at the Centre of the hydrogen fuel system-they will drive demand for hydrogen though their purchasing choices. Effective communication with consumers needs to be clear around the requirements to change their behavior to assist in decabonising transport and heat and use alternative energy sources.

It's important there's recognition that remaining with the status quo is not an option as it will lead to missing the legally binding Climate Change Act targets, higher costs in the longer term and a burden to future generations.

Consumer confidence is built incrementally, with safety concerns addressed over time, in a planned and strategies way; however, is urgency to start now. The benefits associated with hydrogen need to be communicated in such a way that is beneficial to consumers.

We need to highlight air quality improvements, reduced noticed and greater range extension on electric vehicles. As part of this we also need to focus on education, inspiring the younger generation about a cleaner future and up skilling the industry.

(b) Quick Wins:

Focus should be on delivering high profile projects quickly, such as hydrogen use in transport-in particular public transport 
and return to-base fleets. This will build confidence, experience and a supply chain needed tackle more complex challenges such as using hydrogen for heating. Utilising otherwise wasted surplus hydrogen-including banning flaring could be a significant step for the industry. Building on the good work already underway to demon state hydrogen as a community solution, particularly where renewable energy is constrained.

These examples should be used as good models to support further roll out. The limits placed on how bills are calculated and the type of gas used in the network requires expensive interventions and limits the introduction of other gases such as hydrogen. Changing this is a no regrets step on blending hydrogen into the network.

Government should explore implementing policy design to stimulate investment and lead to a levelling of the playing field, given the high levels of government support for other low carbon technologies. It is important to seek parallels and lessons from other transitions, where new technologies and industries have been successfully developed and emissions reduced following policy interventions. One way to do this is to place an obligation on energy companies to supply increasing amounts of decarbonized gas, such as hydrogen, in much the same was that has been done for renewable electricity.

\section{Conclusion}

There should be a focus on stimulating demand in stages. First around transport and heavy industrial processes. This would be followed closely by blending in the gas network, before we can consider a move to $100 \%$ hydrogen for heat. Ports and ferries are areas where uptake of hydrogen solutions will have air quality improvements and a range of benefits over purely battery alternatives.

Heavy industrial processes provide an ideal anchor for hydrogen projects. The construction of a number of regional hubs, supplying hydrogen to meet industrial demand, and blending surplus into the gas network would deliver substantial carbon savings. Gradually increasing the proportion of hydrogen, up to $20 \%$ the point at which current domestic applications can still work, will support the incremental build-up of the capacity to produce hydrogen.

Investments can therefore be incremental, with a reduced risk profile. It will lead to a gradual reduction in the cost of hydrogen for all applications, and prepare for a possible future conversion to a $100 \%$ hydrogen gas network.

Hydrogen is not an all or nothing approach. The hydrogen Fuel System is not entirely dependent on the outcome of $100 \%$ hydrogen for heating. The case for hydrogen in transport, industry, as a blended fuel, and storage medium is sufficient to stand alone.

\section{Future Recommendation}

i. Industrialization \& modernization in the last few decades encountering incremental carbon emission by burning fossil fuel resulting temperature rise of our environment.
According to Paris Agreement, World's temperature rise should not exceed 2 degrees within the following century. To reduce carbon emission, clean \& modern energy should play an important role for healthy environment but it needs to be affordable at price.

ii. Hydrogen fuel is an alternate and sustainable options addressing renewable energy to reduce carbon emission \& Green House Gas (GHG).

iii. FCEV's (Fuel Cell Electric Vehicles) is applicable for heavy-duty vehicle with longer mileage \& transportation. Battery Electric vehicle is the efficient shorter distance transportation system. So both are not competitive for each other's.

iv. Fertilizer industry \& textile industry currently uses SMR (Steam Methane Reforming) technology for generating hydrogen but creates $\mathrm{CO} 2$ which is not clean for the environment. Therefore, Hydrogen fuel technology is an important prospect in the following days.

v. Currently \$3.5-5.00/GGE (gasoline gallon equivalent) is the costing of hydrogen production where $\$ 2.27$ for natural gas.

vi. More research should be run on this Hydrogen technology collaborating with BCSIR, BEPRC, public $\&$ private universities and researchers.

vii. By 2041 hydrogen will have to play an important role in the Bangladesh's in efforts to decarbonize its energy system.

viii. We need to demonstrates the different methods for producing low carbon hydrogen, as well as the opportunities to use it once that energy is created.

ix. The establishment of a hydrogen fuel system is a very real opportunity and within tangible distance. Private sector investment, facilitated by appropriate government policy will allow the Bangladesh to benefit from significant decarbonisation across the entire energy system. Hydrogen fuel could be a major differentiator for the Bangladesh's energy, transport and industrial sector with substantial export potential.

\section{Acknowledgements}

I would like to thank that this work was supported by the Ministry of Science and Technology special allocation Establishment of Hydrogen Energy Laboratory Project, Bangladesh those who were project connected for him kind support and cooperation.

\section{References}

[1] Fraunhofer Institute of Solar, BMW, RWTH. Aachen, Sterner and Stadler (2014): Energisespeicher-Benarf, Technologien, Integration, Mckinsey.

[2] The New Energy outlook (2020), Bloomberg NEF.

[3] Climate Change (2014), Synthesis Report Summary for Policymakers. 
[4] Hydrogen council (2017), Hydrogen Scaling up, a sustainable pathway for the global" energy transition, 30 .

[5] The Daily Star, The Asia News Network. AFP News.

[6] Middle school chemistry, chapter 6, lesson 1 multimedia Retrieved from www.middleschoolchemistry.com/multimedia/chapter6/lesson1.

[7] Hydrogen production: natural gas reforming. Office of Energy efficiency and Renewable Energy Retrieved from www.energy.gov/eere/fuelcells/hydrogen-production-natural-g as-reforming.
[8] Electronics (2020). AC-DC Converters for Electrolyzer Applications: State of the Art and Future Challenges, International Journal of MDPI.

[9] Firehouse (2017), Hydrogen Fuel Cell Vehicles-What First Responders Need to Know Retrieved 2017 from https://www.firehouse.com/rescue/article/12385113/hydrogenfuel-cell-vehicles-what-first-responders-need-to-know-firehou se.

[10] Alea soft Energy foresting (2020), The green hydrogen is the fuel of the future Retrieved 2020 from https://www.aleasoft.com/green-hydrogen-fuel-future. 